\title{
Research on Multi-Stage Composite Loading Process Control Method for Roller Staking of Self-Lubricating Spherical Plain Bearings
}

\author{
Qiang Wang ${ }^{1,2}$, Jigang Chen ${ }^{1,2, *}$, Haili Zhou ${ }^{3}$, Xiaokang Wang ${ }^{1,2}$ and Zhanqi Hu ${ }^{1,2}$ \\ 1 School of Mechanical Engineering, Yanshan University, Qinhuangdao 066004, China; \\ wangq166992@stumail.ysu.edu.cn (Q.W.);wxk@stumail.ysu.edu.cn (X.W.); yjrong@ysu.edu.cn (Z.H.) \\ 2 Aviation Key Laboratory of Science and Technology on Generic Technology of Aviation Self-Lubricating \\ Spherical Plain Bearing, Yanshan University, Qinhuangdao 066004, China \\ 3 College of Mechanical Engineering and Automation, Zhejiang Sci-Tech University, Hangzhou 310018, China; \\ zhouhl@zstu.edu.cn \\ * Correspondence: chenjigang@ysu.edu.cn
}

Citation: Wang, Q.; Chen, J.;

Zhou, H.; Wang, X.; Hu, Z. Research on Multi-Stage Composite Loading Process Control Method for Roller Staking of Self-Lubricating Spherical Plain Bearings. Appl. Sci. 2021, 11, 11127. https://doi.org/10.3390/ app112311127

Academic Editor: Jordi Cusido

Received: 8 November 2021

Accepted: 22 November 2021

Published: 24 November 2021

Publisher's Note: MDPI stays neutral with regard to jurisdictional claims in published maps and institutional affiliations.

Copyright: (c) 2021 by the authors. Licensee MDPI, Basel, Switzerland. This article is an open access article distributed under the terms and conditions of the Creative Commons Attribution (CC BY) license (https:// creativecommons.org/licenses/by/ $4.0 /)$.

\begin{abstract}
The staking quality of Self-lubricating Spherical Plain Bearings (SSPBs) directly affects the safety of aircraft and the service life of bearings. Reliable loading process control methods and precise process parameter indexes will come into the creation of efficacious staking quality. Therefore, this paper aims to analyze the mechanical state of the roller staking process and give a load control method and corresponding parameter indexes for the high-quality roller staking process. First, based on the analysis of quality inspection requirements, five states of the deformation degree of the flanging lip of the $\mathrm{V}$ groove during the roller staking process were proposed, and their relationship with the requirements was studied. Then, the mechanical states corresponding to the five deformation states of the flanging lip deformation were obtained by numerical simulation, and the feeding displacement was determined. Meanwhile, a Multi-Stage Composite Loading (MSCL) process control method was first proposed to control the material damage of the flanging lip, i.e., the rotate speed of the roller tool was constant during the roller staking process, and the displacement-time control was adopted first; when the staking load reaches a staking value, the force-time control was used to make the staking quality meet the requirements. Finally, the staking quality of the MSCL method was verified though the test. The research shows that the feeding displacement needs to be added to the requirements, and the recommended value is $0.5-0.6$ times of the $\mathrm{V}$ groove depth. A good surface quality and non-material-damage of the flanging lip is more likely to be obtained by the MSCL process control method. The research reveals the formation mechanism of process deformation, and gives more precise process control indexes. At the same time, it provides a theoretical reference for more reliable technical standards.
\end{abstract}

Keywords: spherical plain bearing; roller staking process; staking quality; flanging lip deformation; feeding displacement; multi-stage composite loading process

\section{Introduction}

Aviation Self-lubricating Spherical Plain Bearings (SSPBs) are widely used in aerospace and other precision transmission fields because of their advantages of self-lubrication, large carrying capacity, and being maintenance free. Due to the requirements of lightweight and high reliability of aircraft, the staking quality of SSPBs is required to be very strict [1-5]. Therefore, the research on the roller staking process for the installation of the SSPBs (bearing for short) become an increasingly serious public concern. The roller staking process is a developing installation method for SSPBs, which realizes the connection of bearings with housing chamfers through the local and gradual plastic deformation of the flanging lip of the $\mathrm{V}$ groove (also known as incremental forming technology). The incremental forming 
technology uses small deformation to replace the large deformation to minimize forming loads and increase workability [6-8].

Research on the roller staking process is important to improve the reliability of the connection between the bearing and the housing. There is some representative research on the roller staking process: Wang et al. established a 3D elastic-plastic finite element model of the roller staking process, and the influence of the staking time, the staking load and the rotation speed of the roller tool on the staking quality was studied [9]. Zhang et al. proposed staking load analytical equations, and described the metal flow in the roller staking by a 3D finite element model. At the same time, they also designed and fabricated the experimental setup of the roller staking process, and analyzed the influence of the housing chamfering parameters on the staking quality $[10,11]$.

However, to the authors' knowledge, there are fewer studies on the deformation degree of the flanging lip, the feeding displacement control, and its impact on the staking quality after the roller staking process. Defects such as a significant increase in the starting torque of the bearing, material damage and crushing of the flanging lip of the $\mathrm{V}$ groove, and the bearing "locking" often appear after the roller staking process, which seriously affect the staking quality and production efficiency. Therefore, the reliable process-loading control methods and precise process parameter indexes will come into the creation of efficacious staking quality. The purpose of this paper is to analyze the mechanical state of the roller staking process and give a loading control method for the high-quality roller staking process and the parameter indexes. The MS14101-9 self-lubricating spherical plain bearing was used as an example in this paper. Based on the numerical simulation and experimental analysis of the roller staking process, five deformation states of the flanging lip during the roller staking process were defined and the reasonable feeding displacement was determined. Meanwhile, a Multi-Stage Composite Loading (MSCL) process control method was proposed, and the staking quality of this method was verified by tests.

\section{Roller Staking Process}

Figure 1 is a schematic diagram of the process structure of the roller staking process. As can be seen from the figure, it consists of a machine tool, mandrel, roller tool, fixed fixture, workpiece (bearing and housing), and other components. During the roller staking process, the feeding speed-time control and rotate speed-time control functions are provided by the machine tool. Three rollers are evenly distributed at the end of the roller tool, and the diameter of the locus circle of the roller tip is equal to the pitch diameter at the bottom of the $\mathrm{V}$ groove $[9,10]$.

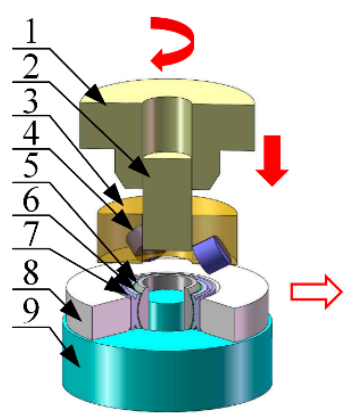

(a)

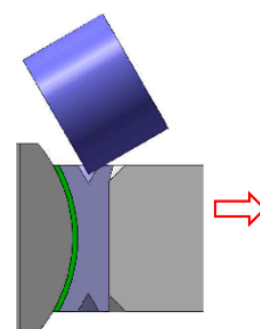

(b)

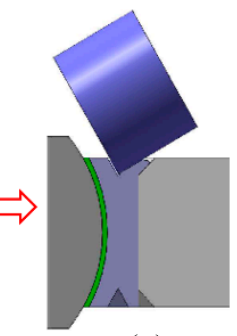

(c)

Figure 1. Schematic diagram of the process structure of the roller staking process: (a) Roller staking; (b) Staking process; (c) Staking completed. 1-machine tool fixture; 2-mandrel; 3-roller tool; 4-roller; 5-inner ring; 6-liner; 7-outer ring; 8-housing; 9-fixed fixture.

The roller staking process is as follows: First, the workpiece is placed in the fixed fixture, and then the roller tool is aligned with the fixed fixture and the roller just comes into contact with the flanging lip, which is the zero position for the roller staking. Control parameters, i.e., feeding speed, rotate speed of the roller tool, or staking load, are set. Then 
the machine tool is started, and the rotation and downward movement of the mandrel drives the rollers at the end of the roller tool to realize revolution around the axis of the mandrel, and to rotate around its own central axis. The flanging lip is deformed by the rolling action and is fitted to the housing chamfer, and then the bearing is connected with the housing.

\section{Relationship between the Flanging Lip Deformation and Quality Inspection Indexes}

\subsection{Five States of the Flanging Lip Deformation History}

In the roller staking process, the staking load makes the flanging lip produce a certain amount of deformation. The rotation flexibility of the bearing will be affected under some strict deformation, and even cause the bearing to work abnormally [12,13]. According to the failure analysis of the bearing in service, improper process quality is an important reason for the bearing failure. For example, during the installation process of the bearing on the ARJ21-700 aircraft, failures such as bearing "locking" have occurred. The main reason for this is that the flanging lip is excessively squeezed during the roller staking process, and then the liner inside the bearing is severely deformed.

The existing quality inspection indexes after roller staking mainly include the minimum push-out load, the maximum starting torque, and the maximum gap between the flanging lip and the housing chamfer. However, the influence between these indexes and process control methods, process control parameters, and the deformation degree of the flanging lip has not been analyzed in depth. The application requirements cannot be met if only one index is met. Combined with the quality inspection indexes, to study the influence of the deformation degree of the flanging lip on the staking quality, the deformation degree of the flanging lip is divided into five states in this paper. Figure 2 shows the schematic diagram of the five limit states of the deformation degree of the flanging lip during the roller staking process $[14,15]$.

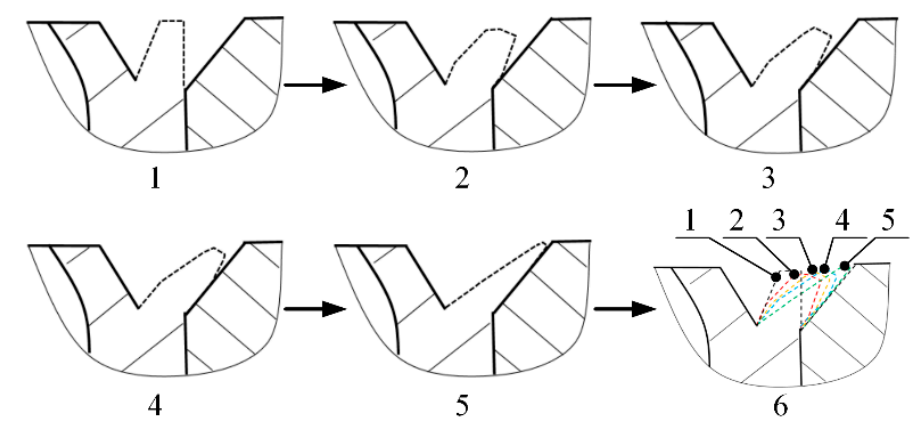

Figure 2. Schematic diagram of the five limit states of the deformation degree of the flanging lip: 1-Initial state; 2-Limit state of "State 2"; 3-Limit state of "State 3"; 4-Limit state of "State 4"; 5-Limit state of "State 5"; 6-Comparison of the five states.

Figure 2 shows that the "State 1" is the initial state, i.e., the state in which the flanging lip of the $\mathrm{V}$ groove just comes into contact with the roller, the flanging lip is not deformed, and the feeding displacement and the staking load are zero. "State 2 " is the state in which the staking process has started, until the maximum feeding limit where the starting torque is not significantly affected; at this stage, the push-out load may not meet the quality requirements. "State 3 " is the state in which the push-out load and the gap between the flanging lip and the housing chamfer meet the requirements after the roller staking, and the starting torque reaches the maximum value specified in the requirements [11]. "State 4 " is the state in which the push-out load meets the requirements; however, the starting torque exceeds the requirements, and the damage degree of the flanging lip reaches the maximum allowed. "State 5" is where the push-out load and the gap meet the requirements, but the starting torque is too large and the flanging lip is severely damaged. At this stage, the bearing cannot be used. 


\subsection{Relationship between the Five States and the Quality Inspection Index}

The influence of the deformation degree of the flanging lip on the starting torque, push-out load, and other quality inspection indexes after roller staking determines the bearing performance. It is necessary to study the variation relationship of these five states, in order to reasonably control the staking time, the feeding displacement, and the staking load, and to grasp the staking state and damage degree. The sequence diagram of these five states during the roller staking process is shown in Figure 3 , where $\Delta_{1}$ and $\Delta_{2}$ in the figure are the minimum and maximum limit deformation degree of reaching the standard, respectively. As can be seen from the figure, when "State 2" transitions to "State 3 " and "State 3 " transitions to "State 4 ", the staking quality meets the quality requirements. These states are included with each other, and are not independent of each other. The requirements are exceeded by "State 5" and the bearing is invalidated.

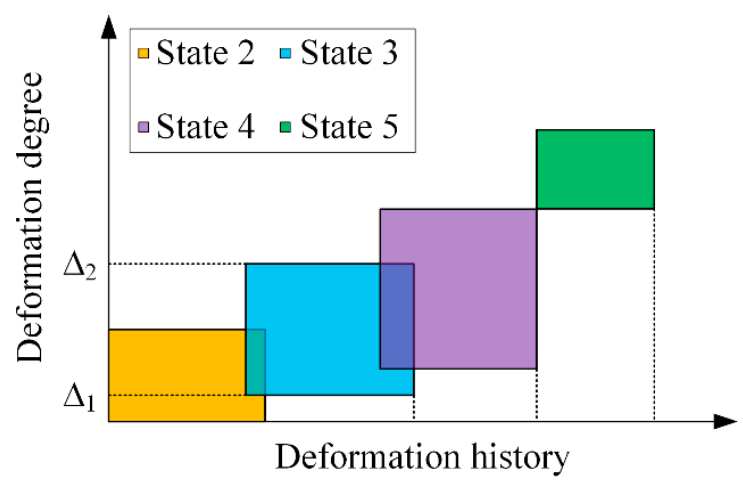

Figure 3. Sequence diagram of the five states during the roller swaging process.

\section{Numerical Simulation of the Roller Staking Process}

In this paper, the type of MS14101-9 bearing was selected as an example, and its main structure is shown in Figure 4. The main parameters of the selected bearing are shown in Table 1 . The mechanical states of these five states were analyzed by numerical simulation using Deform software [16-19]. Figure 5 shows the simulation model established by the displacement-time control of the uniform speed feeding.

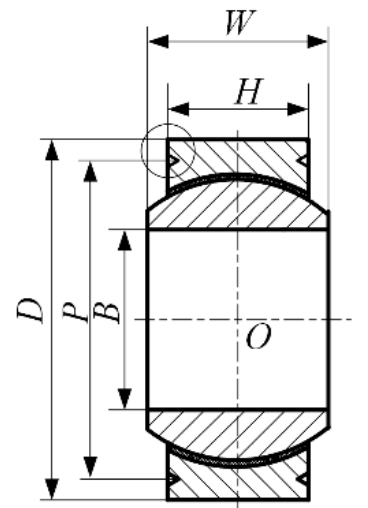

(a)

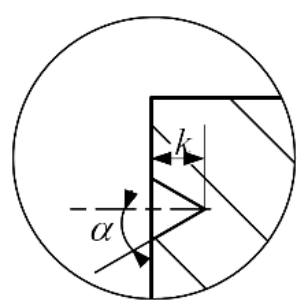

(b)

Figure 4. Schematic of main structure of the MS14101-9 bearing: (a) Structure of the bearing; (b) Structure of the V groove. 
Table 1. Main parameters of the MS14101-9 bearing.

\begin{tabular}{cc}
\hline Parameters & Values \\
\hline Outside diameter $D / \mathrm{mm}$ & 27.78 \\
\hline Inner hole diameter $B / \mathrm{mm}$ & 14.29 \\
\hline Outer ring width $H / \mathrm{mm}$ & 11.10 \\
\hline Inner ring width $W / \mathrm{mm}$ & 14.27 \\
\hline V groove depth $k / \mathrm{mm}$ & 1.40 \\
\hline Groove pitch diameter $P / \mathrm{mm}$ & 24.64 \\
\hline Groove angle $\alpha{ }^{\circ}$ & 30 \\
\hline
\end{tabular}

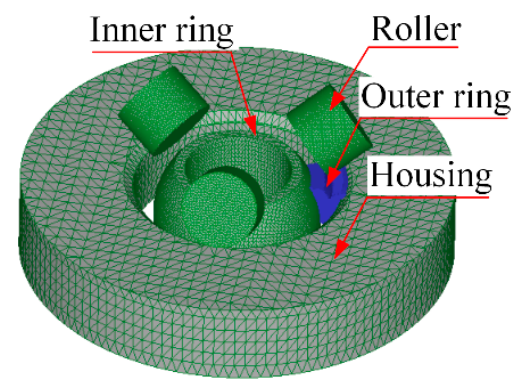

Figure 5. Schematic diagram of simulation model of the roller swaging process.

Since the deformation degrees of the flanging lip were mainly studied, and the mechanical state of the inner surface of the outer ring can be used to measure the extrusion state of the liner during the simulation, the liner is ignored, and the model is simplified. At the same time, the rigidity of the roller is relatively high, and the housing deformation is relatively small, therefore, the roller and housing were defined as rigid bodies, the inner ring was defined as an elastomer, and the outer ring was defined as an elastoplastic body. The material of the outer ring is 17-4PH [10], and the stress-strain curve was obtained by tensile test according to the standard of ISO6892-1: 2009. Its elastic modulus is $213 \mathrm{GPa}$ and Poisson's ratio is 0.27 . The material of the inner ring is $9 \mathrm{Cr} 18$, and its elastic modulus is 232 GPa and Poisson's ratio is 0.283 . The friction coefficients between the inner and outer rings, and between the outer ring and the housing were set to 0.07 and 0.15 , respectively. Zero friction was set between the roller and the flanging lip.

To improve the calculation efficiency, 1/12 of the axisymmetric structure of the outer ring was selected for analysis. Although the rotational loading has surface asymmetry, the simulation model of the middle part of the outer ring is far away from the boundary, and based on the Saint-Venant's principle, the mechanical state in the middle of the outer ring model is representative of the simulation results. Therefore, the data in the middle position of the $1 / 12$ model were selected for data processing. The details of the numerical model are present in Table 2. In the boundary conditions settings, the revolution speed of the roller tool is $20 \mathrm{rad} / \mathrm{s}$, the rotate speed of the roller is $48.24 \mathrm{rad} / \mathrm{s}$, and the roller feeding speed was $0.1 \mathrm{~mm} / \mathrm{s}$. The roller tool size was omitted from the description.

Table 2. The details of the numerical model.

\begin{tabular}{ccccc}
\hline Parameters & Inner Ring & Outer Ring & Housing & Roller \\
\hline Mesh size $(\mathrm{mm})$ & 0.3 & 0.13 & 1.8 & 0.8 \\
\hline Element type & Tetrahedral & Tetrahedral & Tetrahedral & Tetrahedral \\
\hline Element numbers & 16,674 & 47,459 & 5870 & 7156 \\
\hline
\end{tabular}




\section{Results and Discussion}

\subsection{Equivalent Stress and Material Damage Corresponding to the Five States}

\subsubsection{Equivalent Stress Analysis}

To obtain the mechanical states corresponding to the five states, the simulation will be performed until the material of the flanging lip has incurred large damage and been squeezed out of the housing chamfer [20-22]. "State 1" is the state where the flanging lip just comes into contact with the roller, which is the simulation start time. Figure 6 shows the flanging lip deformation and equivalent stress of the outer ring in the latter four states.

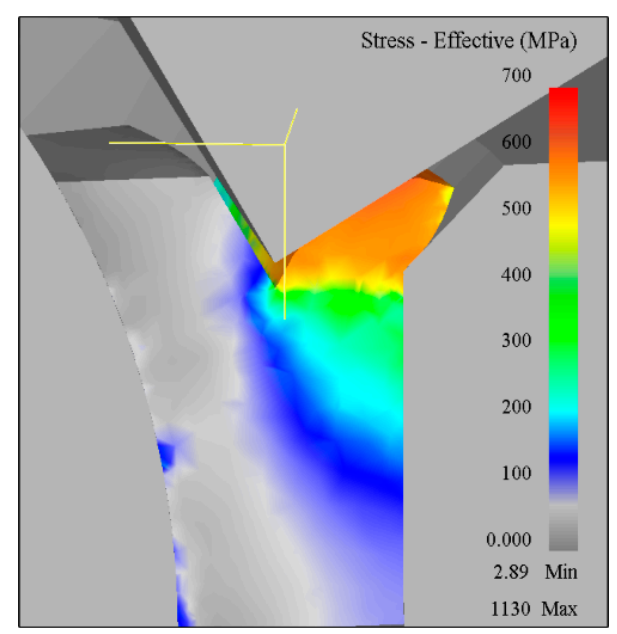

(a)

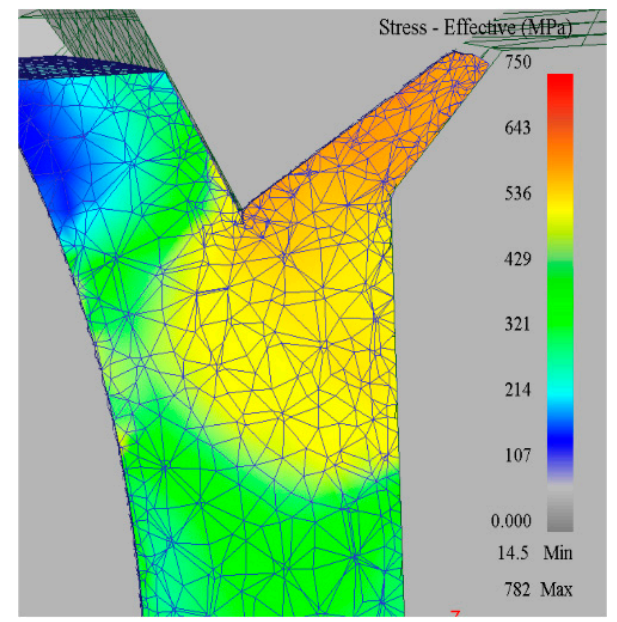

(c)

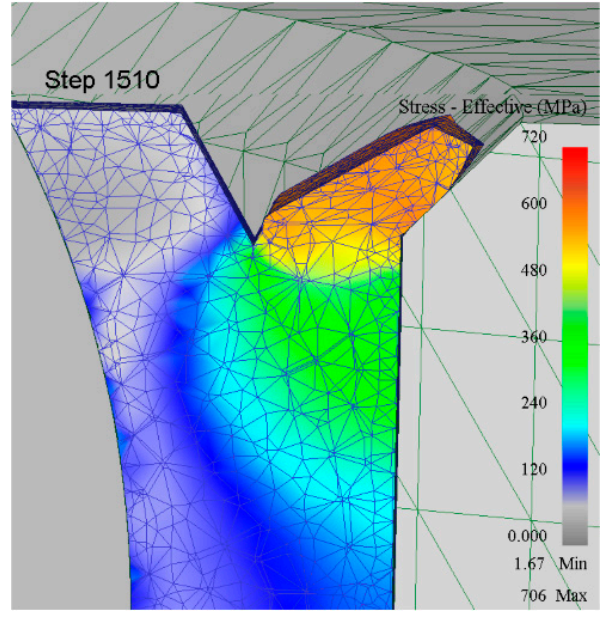

(b)

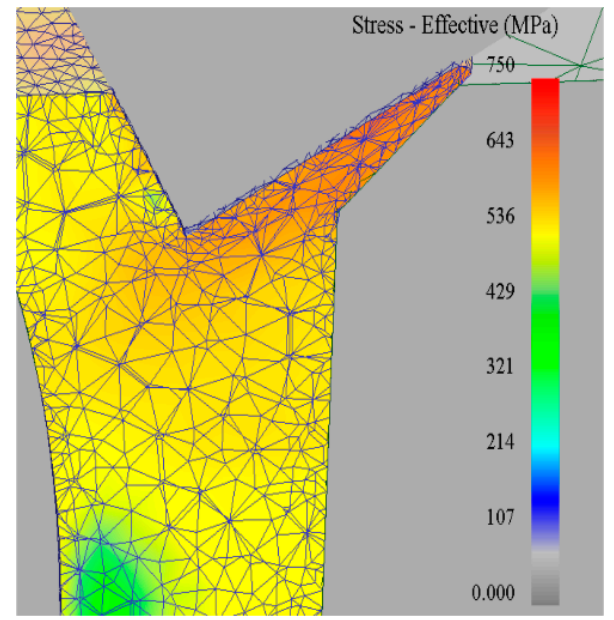

(d)

Figure 6. Flanging lip deformation and equivalent stress of the outer ring in the latter four states: (a) Equivalent stress of "State 2"; (b) Equivalent stress of "State 3"; (c) Equivalent stress of "State 4"; (d) Equivalent stress of "State 5".

Figure 6a shows the equivalent stress of the outer ring in the limit state of "State 2", at this time, the flanging lip deformation has reached a certain degree, the maximum stress value is about $500 \mathrm{MPa}$. Meanwhile, there is no obvious effect on the inside of the outer ring. The staking quality in this state is mainly evaluated by the push-out load index. Figure $6 \mathrm{~b}$ shows the equivalent stress of the outer ring in the limit state of "State 3", and the maximum stress value is about $580 \mathrm{MPa}$. At this time, the deformation quality is better, the fit is relatively stable, and the push-out load meets the requirements. If the stress is controlled below a small value, the bearing will not be "locking". This state is mainly controlled by the staking load, and thus the stress-strain distribution in the deformation area can be controlled. Figure $6 \mathrm{c}$ shows the equivalent stress of the outer ring in the limit 
state of "State 4". At this time, the degree of fit between the flanging lip and the housing chamfer is improved, and the push-out load meets the requirements. However, the stress inside the outer ring is relatively large, the maximum stress value is about $610 \mathrm{MPa}$, and the limit state of undamaged material on the flanging lip is reached. In practice, in this state, the quality defects of the bearing "locking" often appear after roller staking. Figure $6 \mathrm{~d}$ shows the equivalent stress of the outer ring at the limit state of "State 5". At this time, the structure of the flanging lip becomes thinner, the stress inside the outer ring is larger, and the maximum stress value is about $650 \mathrm{MPa}$. The material of the flanging lip is excessively squeezed or even squeezed out of the housing chamfer. Products in this state cannot meet practical application; therefore, feeding displacement must be controlled to avoid flanging lip deformation.

\subsubsection{Material Damage Analysis}

To analyze the influence of the material damage of the flanging lip deformation, the simulations were carried out on the material damage of the flanging lip in the latter four states. Figure 7 shows the damage degree of the flanging lip in the latter four states.

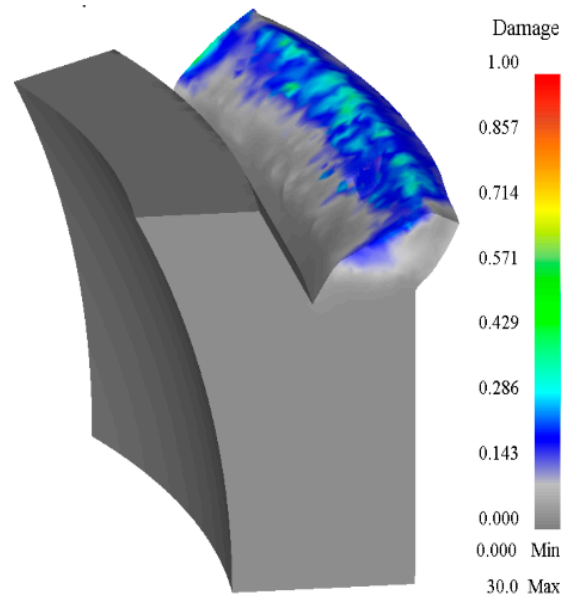

(a)

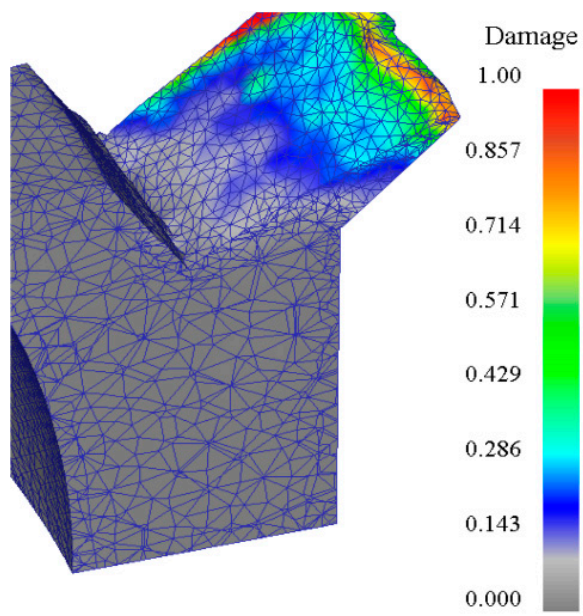

(c)

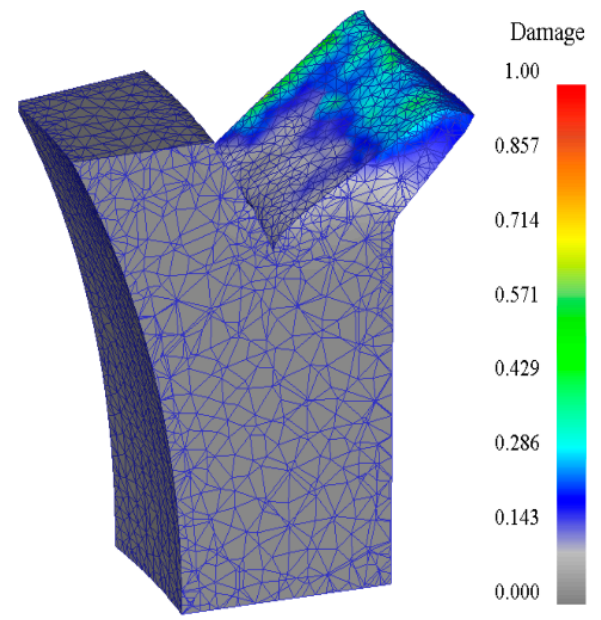

(b)

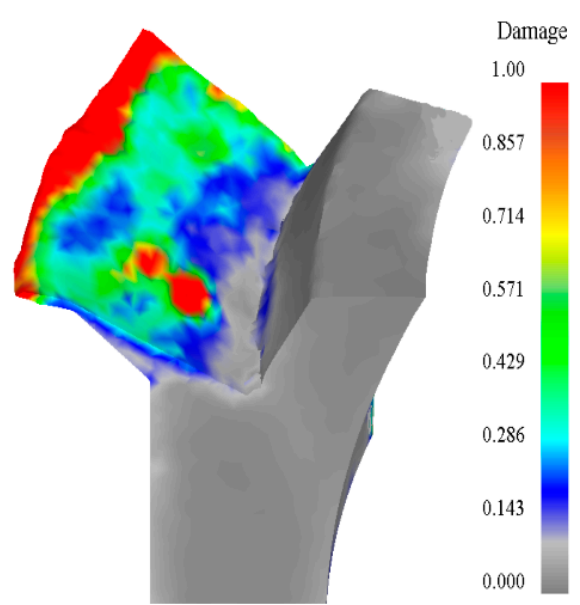

(d)

Figure 7. Damage degree of the flanging lip in the latter four states: (a) Material damage in "State 2"; (b) Material damage in "State 3"; (c) Material damage in "State 4"; (d) Material damage in "State 5".

Figure 7a shows the damage contours in the limit state of "State 2". At this time, the flanging lip has no surface damage or only minor surface damage, and the material damage can be ignored. Figure $7 \mathrm{~b}$ shows the damage contours in the limit state of "State 3". 
At this time, obvious surface damage appears on the flanging lip with damage values ranging from $0.14-0.28$. The damage occurs at a depth of about $1 / 8-1 / 6$ of the flanging lip thickness in the depth direction; this state has no significant impact on the practical application. The stress and deformation degree should be controlled so that the damage depth does not exceed $1 / 4$ of the flanging lip thickness, and then requirements can be met. Figure 7c shows the damage contours in the limit state of "State 4". At this time, although the fit between the flanging lip and the housing chamfer is stable, the damage value of the flanging lip is larger. The material on the outer edge of the flanging lip has been penetrated in the area where damage values is about 0.5 , and the damage value of the flanging lip tip reaches 0.86 . Figure $7 \mathrm{~d}$ shows the damage contours in the limit state of "State 5 ". At this time, the material on the outer edge of the flanging lip is excessively squeezed, and most of its damage value is above 0.85 . The quality defects of this state cannot meet the practical application.

The analysis of the different deformation degrees shows that the loading control parameters and the loading control method of the roller staking process should be comprehensively considered. A better staking quality can be obtained by making the stress-strain and deformation degree of the flanging lip in "State 3" as good as possible, i.e., quality inspection requirements of push-out load, the fit between the flanging lip and the housing chamfer, and the starting torque are all met.

\subsection{Analysis of Feeding Displacement and Staking Load}

The feeding displacement and the staking load directly determines the deformation degree of the flanging lip, and determines the working performance of the bearing after the roller staking process. Therefore, reasonable control of the loading process of the feeding displacement and the staking load is very necessary to control the staking quality $[23,24]$. The relationship curve between the feeding displacement and the staking load was obtained for the limit states of the "State 5" and "State 3" are shown in Figure 8, respectively.

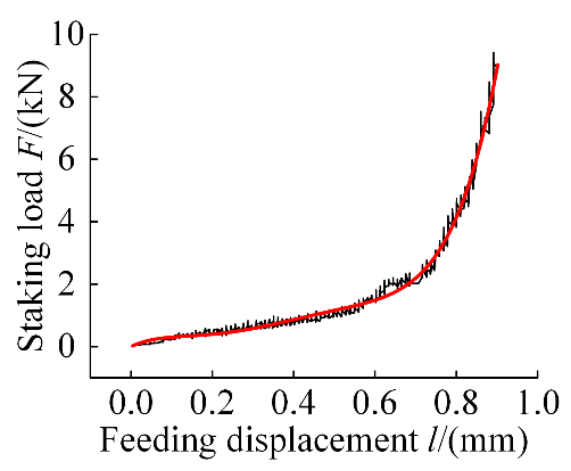

(a)

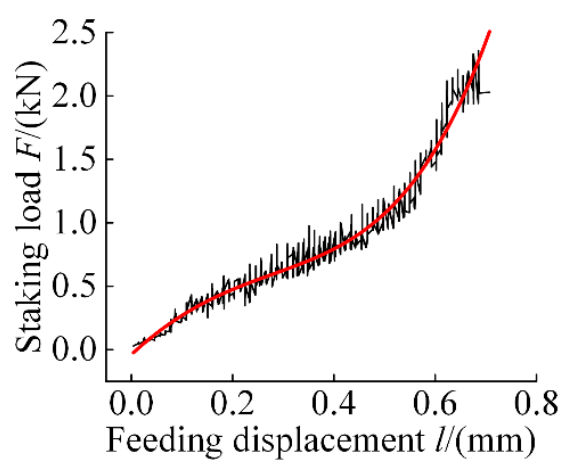

(b)

Figure 8. Relationship curve between the feeding displacement and the staking load: (a) the whole process of downward to "State 5"; (b) the process of downward to "State 3".

The black line in Figure 8 is the staking load curve obtained by finite element numerical simulation, and the red line is the smooth curve fitted to it. It can be seen from Figure $8 \mathrm{a}$ that in the initial stage of the roller staking process, the staking load increases linearly with the change of the feeding displacement. When the feeding displacement is about $0.70 \mathrm{~mm}$, the corresponding deformation state is "State 3" (as shown in Figure 8b). After this state, the staking load increases sharply. For other types of bearings mainly used in aviation at this stage, the roller staking process was analyzed using the same simulation method, and the general rule is as follows: if the feeding displacement is approximately equal to about $0.5-0.6$ times depth of the $\mathrm{V}$ groove $(k)$ and keep the staking load at a certain level, a better staking quality can be obtained, and most of the bearings after staking meet the requirement of the practical application. 


\subsection{MSCL Control Method}

The above research is based on the analysis of the "displacement-time control of uniform speed feeding". Through the analysis of the deformation degree of the flanging lip and the process quality, it is shown that the feeding displacement and the staking load should be controlled. In practice, the "displacement-time control of uniform speed feeding" or "force-time control of constant force feeding" is often adopted [25-28]. However, the above analysis shows that when the "displacement-time control of uniform speed feeding" is adopted, it causes bearing "locking" and material damage at a later stage of the roller staking process $[10,29]$. For the "force-time control of constant force feeding", the contact position between the roller and the flanging lip is likely to be pressed out of a "pit" in the initial stage of the process, which will damage the material of the flanging lip [30,31]. Therefore, a "Multi-Stage Composite Loading (MSCL)" control method is proposed in this study to realize the effective control of the staking load, feeding displacement, and deformation degree of the flanging lip.

The schematic diagram of the speed-time and force-time curves of the three methods are shown in Figure 9. The solid line in the figure represents "active monitoring" and the dotted line represents "passive control". Figure 9a shows the control method of the "displacement-time control of uniform speed feeding", which is commonly used at present. During the roller staking process, the rotate speed of the roller tool and the feeding speed are constant, and the staking load is monitored. In the latter period of the roller staking process, the staking load increases sharply, and it is easy for staking to not be in place or be excessively squeezed, and even for there to be material damage of the flanging lip. Figure $9 \mathrm{~b}$ shows the control method of the "force-time control of constant force feeding". During the roller staking process, the rotate speed of the roller tool and the staking load are constant, and the feeding displacement is monitored. In the early period of the roller staking process, the contact area between the roller and the flanging lip is small, which makes the feeding speed at the beginning of the roller staking too large. It is easy to press out a "pit" or defects such as large deformation of the flanging lip, resulting in material damage at the flanging lip tip. At the same time, the frictional contact between the roller tool and the flanging lip may be unstable, resulting in poor surface quality of the flanging lip.

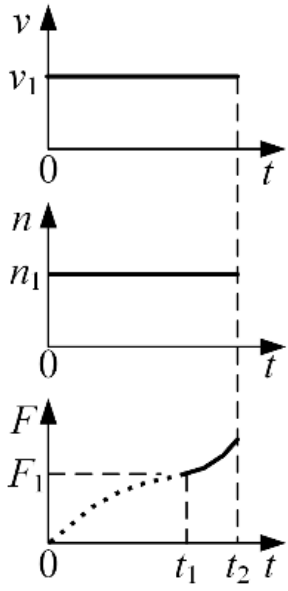

(a)

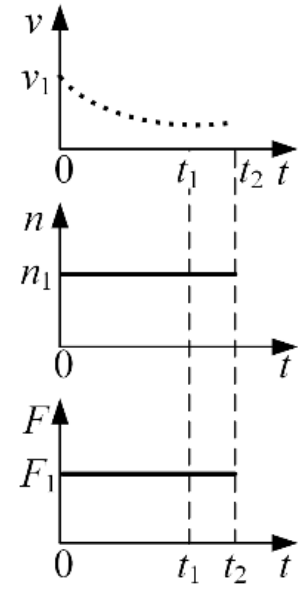

(b)

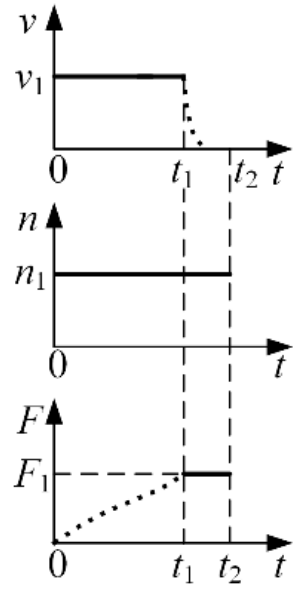

(c)

Figure 9. Schematic diagram of the speed-time and force-time curves of the three process-loading control methods: (a) Displacement-time control; (b) Force-time control; (c) MSCL control.

Based on the analysis of the above two process-loading control methods, a new process-loading control method is proposed in this paper to reduce staking quality defects. Figure 9c shows the MSCL control method, i.e., the rotate speed of the roller tool is constant 
during the roller staking process, and multi-stage control is adopted. The control process is as follows: in the time period of $0-t_{1}$, displacement-time control is adopted, the feeding speed $\left(v_{1}\right)$ remains constant, and the staking load is monitored. When the staking load reaches $F_{1}$, the force-time control for the time period of $t_{1}-t_{2}$ is entered. The staking load $F_{1}$ remains constant, the feeding displacement is monitored to (0.5-0.6) $k$, and rolling continues for a while to polish the surface of the flanging lip, and then the control process is completed. The variation curves of the staking load and feeding speed with staking time for the three process-loading control methods during the numerical simulation are given, as shown in Figure 10. The comparison of the process characteristics and the staking quality inspection results of the three process-loading control methods (displacement-time control, force-time control and MSCL control) are shown in Table 3.

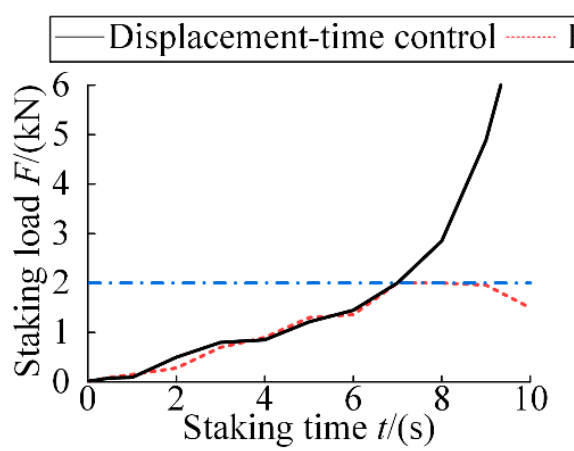

(a)

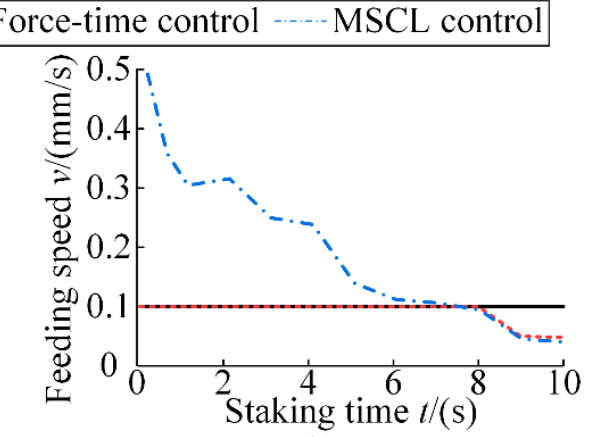

(b)

Figure 10. Qualification rates of different quality indexes under three loading control methods: (a) Staking load-time curve; (b) Feeding speed-time control.

Table 3. Comparison of the process characteristics and staking quality inspection results of the three process-loading control methods.

\begin{tabular}{|c|c|c|}
\hline $\begin{array}{l}\text { Process-Loading Control } \\
\text { Methods }\end{array}$ & Process Characteristics & $\begin{array}{l}\text { Comparison of Staking } \\
\text { Quality Inspection Results }\end{array}$ \\
\hline Displacement-time control & $\begin{array}{l}\text { The feeding speed is constant. } \\
\text { With the increase of feeding } \\
\text { displacement, the staking load } \\
\text { will increase sharply, and it is } \\
\text { not easy to be controlled in } \\
\text { the later stage of the process. }\end{array}$ & $\begin{array}{l}\text { The material of the flanging lip } \\
\text { is easily crushed, and the } \\
\text { bearing "locking" is often } \\
\text { appeared. More than } 40 \%-50 \% \\
\text { of the bearings exceed the } \\
\text { starting torque standard and } \\
\text { required subsequent } \\
\text { adjustment. The process quality } \\
\text { yield is less than } 60 \% \text {. }\end{array}$ \\
\hline Force-time control & $\begin{array}{l}\text { The staking loading is } \\
\text { constant, and the feeding } \\
\text { speed in the initial stage is } \\
\text { faster; the contact surface is } \\
\text { small, which is easy to cause } \\
\text { the deformation instability. } \\
\text { The surface quality is not easy } \\
\text { to control. }\end{array}$ & $\begin{array}{l}\text { The flanging lip is likely to be } \\
\text { pressed out a "pit" in the initial } \\
\text { stage, inadequate staking or } \\
\text { over-staking often appears, and } \\
\text { the surface quality of flanging } \\
\text { lip is uneven. The process } \\
\text { quality yield is less than } 75 \% \text {. }\end{array}$ \\
\hline MSCL control & $\begin{array}{l}\text { First, the feeding speed is } \\
\text { controlled so that the staking } \\
\text { load gradually increases to a } \\
\text { certain value, then the staking } \\
\text { load is controlled to be } \\
\text { constant, and the feeding } \\
\text { displacement is monitored. } \\
\text { The deformation is stable. }\end{array}$ & $\begin{array}{l}\text { There is no bearing "locking" } \\
\text { phenomenon, the starting } \\
\text { torque is relatively uniform, the } \\
\text { fit between the flanging lip and } \\
\text { the housing chamfer is tightly } \\
\text { and the surface quality is good. } \\
\text { The process quality yield is } \\
\text { more than } 90 \% \text {. }\end{array}$ \\
\hline
\end{tabular}




\section{Application Verification Research of MSCL}

To verify the effectiveness of the MSCL control method, the experimental verification was carried out by the roller staking equipment. The MS14101-9 bearing was selected, and the flanging lip deformation of the $\mathrm{V}$ groove under different states was analyzed through experiments. Figure 11 shows the test machine for the roller staking process. The speed-time control was adopted first, and the rotate speed of the roller tool was set to $200 \mathrm{r} / \mathrm{min}$ [32], after the feeding speed was gradually increased to $0.1 \mathrm{~mm} / \mathrm{s}$, and keep it constant and continue rolling. When the staking load was detected to reach $2000 \mathrm{~N}$, it was kept constant, and then force-time control was adopted, when the feeding displacement reached $0.5 k$ (i.e., $0.71 \mathrm{~mm}$ ), feeding was stopped and rolling continued for 3-5 turns for surface quality of the flanging lip.

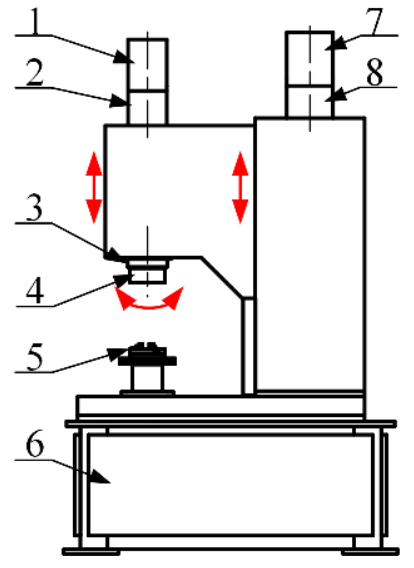

(a)

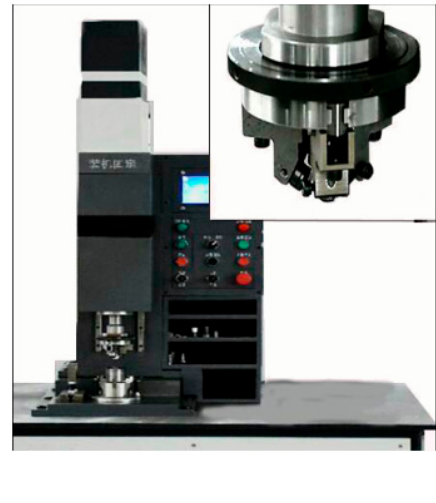

(b)

Figure 11. Schematic diagram of the roller swaging apparatus and the structure of the roller tool: (a) Schematic diagram of the roller swaging apparatus; (b) Real test machine. 1 -Electric cylinder; 2-Pressure transducer; 3-Machine tool fixture; 4-Roller tool; 5-Fixed fixture; 6-Frame; 7-Drive motor; 8-Reducer.

Figure 12 shows the cross-sectional view and the state comparison of specimens under MSCL control and displacement-time control. Figure 12a shows the initial deformation state of the flanging lip with MSCL control method. Figure 12b shows the "State 2" of MSCL control method, at this time. A fit begins to appear between the flanging lip and the housing chamfer. Figure 12c shows the "State 3" of MSCL control method. The fit quality is better, and the requirements and bearing performance are met. Figure $12 \mathrm{~d}$ shows the "State 5" of displacement-time control method. The fit is tighter; however, it is obvious that the flanging lip is excessively squeezed, and material damage occurs.

Similarly, for the other two process-loading control methods, 50 bearings were selected for the roller staking tests. Figure 13 shows the qualification rate comparison of different quality indexes (starting torque, surface quality, and fit between the flanging lip and the housing chamfer after roller staking) under the three process-loading control methods. It can be seen from the figure that the qualification rate of the bearing can be significantly improved by the MSCL loading control method. Through the test comparison and analysis, it can be seen that when the MSCL control method is adopted, the staking quality can be controlled more easily, and more bearings can be guaranteed to be in "State 3" after the roller staking process, and thereby increase the yield rate of the bearing. 


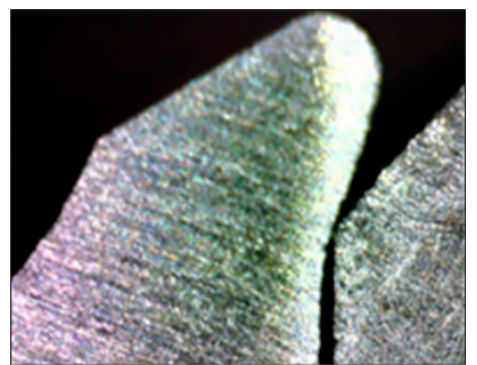

(a)

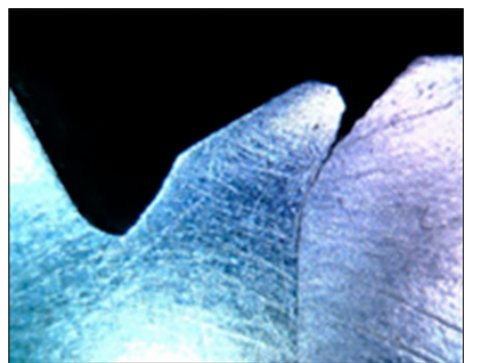

(c)

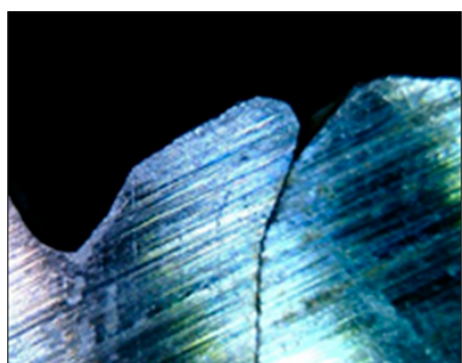

(b)

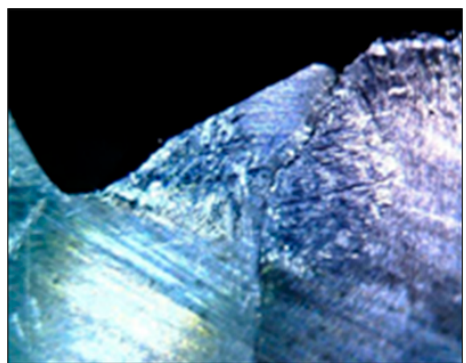

(d)

Figure 12. Cross-sectional view and state comparison of specimens under MSCL control and displacement-time control: (a) initial deformation controlled by MSCL; (b) "State 2" of MSCL; (c) "State 3" of MSCL; (d) "State 5" of displacement-time control.

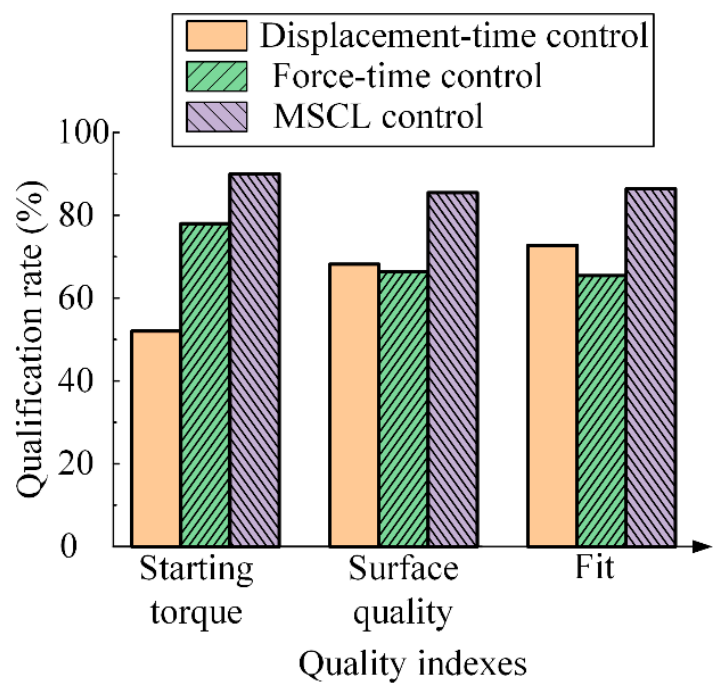

Figure 13. Qualification rates of different quality indexes under three loading control methods.

\section{Conclusions}

In this paper, the deformation degree of the flanging lip of the $\mathrm{V}$ groove is researched after the roller staking process. Taking the MS14101-9 bearing as an example, numerical analysis and experimental verification of the deformation degree of flanging lip and the loading control method during the roller staking process were carried out. The following conclusions can be drawn:

(1) Based on the feeding displacement, the push-out load, the starting torque, and the deformation characteristics of the flanging lip, it is proposed to divide the deformation degree of the flanging lip into five states after roller staking. "State 1 " is the initial state; "State 2" is the limit state in which the starting torque is not significantly affected; "State 3" is the limit state in which the push-out load meets the quality inspection requirements and the starting torque reaches the maximum value specified in the standard after roller 
staking; "State 4" is the limit state in which the starting torque exceeds the requirements and the damage degree of the flanging lip is out at the maximum allowable limit. "State 5" is when the push-out load meets the requirements, but the starting torque is too large and the flanging lip is severely damaged.

(2) The ideal state for the good staking quality and working performance of the bearing is "State 3". The aforementioned five states have a timing sequence and a certain overlap. Before the maximum limit state of "State 3", the staking loads are almost linear, and the surface quality of the flanging lip is better.

(3) The control method of "Multi-Stage Composite Loading (MSCL)" is proposed by analyzing the displacement-time control and the force-time control, i.e., the rotate speed of the roller tool is constant, and the MSCL control is adopted during the roller staking process. The effectiveness of the MSCL control method was verified by the roller staking test. At the same time, the feeding displacement is proposed as a reference index, and it is suggested that the feeding displacement is $0.5-0.6$ times the $V$ groove depth.

The above research analyzed the mechanical state of the roller staking process, and the revealed deformation mechanism of the flanging lip of the $\mathrm{V}$ groove during the roller staking process. In terms of the roller staking technology of SSPBs, a precise processloading control method and parameter indexes are given, which provides a theoretical reference for further formation about more reliable technical standards, and has been well applied in practice.

Author Contributions: Conceptualization, Q.W.; data curation, Q.W., J.C. and Z.H.; software, X.W. and H.Z.; supervision, J.C., H.Z. and Z.H.; writing-original draft preparation and formal analysis, Q.W.; writing-review and editing, X.W., H.Z. and Z.H. All authors have read and agreed to the published version of the manuscript.

Funding: This research was funded by the scientific research start-up funding project of Zhejiang SciTech University of China, grant number 11132932612009, Funding projects for the central government to guide the development of local science and technology of China, grant number 206Z1008G and the Science and Technology Projects of Qinhuangdao, grant number 201901B003.

Institutional Review Board Statement: Not applicable.

Informed Consent Statement: Not applicable.

Data Availability Statement: All data generated or analyzed during this study are included in this article.

Acknowledgments: The authors want to thank Aviation Key Laboratory of Science and Technology on Generic Technology of Aviation Self-Lubricating Spherical Plain Bearing.

Conflicts of Interest: The authors declare no conflict of interest.

\section{References}

1. Shen, X.J.; Liu, Y.F.; Cao, L.; Chen, X.Y. Numerical Simulation of Sliding Wear for Self-lubricating Spherical Plain Bearings. J. Mater. Res. Technol. 2012, 1, 8-12. [CrossRef]

2. Qiu, M.; Miao, Y.W.; Li, Y.C.; Lu, J.J. Film-forming mechanisms for self-lubricating radial spherical plain bearings with hybrid PTFE/aramid fabric liners modified by ultrasonic. Tribol. Int. 2015, 87, 132-138. [CrossRef]

3. Hu, Z.Q.; Li, W.; Yang, Y.L.; Fan, B.L.; Zhou, H.L. Thermal error compensation of the wear-depth real-time detecting of self-lubricating spherical plain bearings. Chin. J. Mech. Eng. 2018, 31, 35-47. [CrossRef]

4. Li, W.; Hu, Z.Q.; Yang, Y.L.; Qi, X.W.; Zhou, H.L. Credibility in evaluating on-line wear-depth detection of self-lubricating spherical plain bearings. Adv. Mech. Eng. 2016, 8, 1687814016666746. [CrossRef]

5. Qiu, M.; Li, Y.C.; Chen, L.; Bai, Y.X. Effects of rare earth treatment on tribological properties of self-lubricating spherical plain bearings. Wear 2013, 305, 274-279. [CrossRef]

6. Zhang, S.; Shu, X.D.; Shi, J.N.; Li, Z.X. Multi-pass stamping forming a concave ring. Appl. Sci. 2020, 10, 6434. [CrossRef]

7. Jin, J.S.; Qi, Z.M.; Wang, X.Y.; Lei, D. An incremental die forging process for producing helical tubes. Int. J. Adv. Manuf. Technol. 2016, 85, 99-114. [CrossRef]

8. Xia, Y.X.; Shu, X.D.; Zhu, Y.; Li, Z.X. Influence of process parameters on forming load of variable-section thin-walled conical parts in spinning. Appl. Sci. 2020, 10, 5932. [CrossRef] 
9. Wang, Q.; Chen, J.G.; Liu, C.X.; Zhao, J.H.; Hu, Z.Q. Research on loading parameters of roller swaging process of self-lubricating spherical plain bearings. Int J. Adv. Manuf Technol 2021. [CrossRef]

10. Zhang, Q.L.; Hu, Z.Q.; Su, W.W.; Zhou, H.L.; Qi, X.W.; Yang, Y.L. Investigation on housing chamfer parameters in roller swaging for self-lubricating spherical plain bearings assembly. Int. J. Adv. Manuf. Technol. 2017, 95, 1087-1099.

11. Zhang, Q.L.; Hu, Z.Q.; Yang, Y.L.; Ma, J.; Qi, X.W. Investigation of the roller swaging process for self-lubricating spherical plain bearings assembly. J. Mater. Process. Technol. 2017, 241, 36-45. [CrossRef]

12. Zhang, Q.; Zhang, Y.S.; Cao, M.; Ben, N.Y.; Ma, X.W.; Ma, H.X. Joining process for copper and aluminum tubes by rotary swaging method. Int. J. Adv. Manuf. Technol. 2017, 89, 163-173. [CrossRef]

13. Zhang, Q.; Jin, K.Q.; Mu, D. Tube/tube Joining Technology by Using Rotary Swaging Forming Method. J. Mater. Process. Tech. 2014, 214, 2085-2094. [CrossRef]

14. Mohamed, F.A.; El-Abden, S.Z.; Abdel-Rahman, M. A rotary flange forming process on the lathe using a ball-shaped tool. J. Mater. Process. Technol. 2005, 170, 501-508. [CrossRef]

15. Groche, P.; Wohletz, S.; Brenneis, M.; Pabst, C.; Resch, F. Joining by forming-A review on joint mechanisms, applications and future trends. J. Mater. Process. Technol. 2014, 214, 1972-1994. [CrossRef]

16. Roy, M.J.; Maijer, D.M. Analysis and modelling of a rotary forming process for cast aluminium alloy A356. J. Mater. Process. Technol. 2015, 226, 188-204. [CrossRef]

17. Tullu, A.; Lee, B.S.; Hwang, H.Y. Surrogate model based analysis of inter-ply shear stress in fiber reinforced thermoplastic composite sheet press forming. Appl. Sci. 2020, 10, 5499. [CrossRef]

18. Li, W.; Hu, Z.Q.; Yang, Y.L.; Fan, B.L.; Zhou, H.L. Modeling and verification of comprehensive errors of real-time wear-depth detecting for spherical plain bearing tester. J. Cent. South. Univ. 2017, 24, 533-545. [CrossRef]

19. Lu, J.J.; Qiu, M.; Li, Y.C. Numerical analysis of self-lubricating radial spherical plain bearings and investigations on fatigue damage mechanisms of the liner. Tribol. Int. 2016, 96, 97-108. [CrossRef]

20. Golchin, A.; Simmons, G.F.; Glavatskih, S.B. Break-away friction of PTFE materials in lubricated conditions. Tribol. Int. 2012, 48, 54-62. [CrossRef]

21. Abdo, B.; El-Tamimi, A.; Nasr, E.A. Rotary ultrasonic machining of alumina ceramic: An experimental investigation of tool path and tool overlapping. Appl. Sci. 2020, 10, 1667. [CrossRef]

22. Moon, H.K.; Lee, M.C.; Joun, M.S. An approximate efficient finite element approach to simulating a rotary forming process and its application to a wheel-bearing assembly. Finite Elem. Anal. Des. 2007, 44, 17-23. [CrossRef]

23. Bui, Q.V.; Ponthot, J.P. Numerical simulation of cold roll-forming processes. J. Mater. Process. Technol. 2008, $202,275-282$. [CrossRef]

24. Gong, X.P.; Li, M.Z.; Lu, Q.P.; Peng, Z.Q. Research on continuous multi-point forming method for rotary surface. J. Mater. Process. Technol. 2012, 212, 227-236. [CrossRef]

25. Daud, Y.M.; Lucas, M.; Huang, Z.H. Modelling the effects of superimposed ultrasonic vibrations on tension and compression tests of aluminium. J. Mater. Process. Technol. 2007, 186, 179-190. [CrossRef]

26. Diez, M.; Kim, H.E.; Serebryany, V.; Dobatkin, S.; Estrin, Y. Improving the mechanical properties of pure magnesium by three-roll planetary milling. Mater. Sci. Eng. A-Struct. 2014, 612, 287-292. [CrossRef]

27. Toda, K.; Ishii, T.; Kashiwagi, S.; Mitarai, T. Development of hub units with shaft clinching for automotive wheel bearings. KOYO Eng. J. Engl. Ed. 2001, 158, 21-37.

28. Boehmermann, F.; Hasselbruch, H.; Herrmann, M.; Riemer, O.; Mehner, A.; Zoch, H.W.; Kuhfuss, B. Dry rotary swagingapproaches for lubricant free process design. Int. J. Precis. Eng. Manuf.-GT 2015, 2, 325-331. [CrossRef]

29. Xu, T.F.; Yang, L.H.; Wang, K. Characteristics of duplex angular contact ball bearing with combined external loads and angular misalignment. Appl. Sci. 2020, 10, 5756. [CrossRef]

30. Lima, M.; Folio, F.; Mischler, S. Microstructure and surface properties of laser-remelted titanium nitride coatings on titanium. Surf. Coat. Technol. 2005, 199, 83-91. [CrossRef]

31. Lim, S.J.; Choi, H.J.; Lee, C.H. Forming characteristics of tubular product through the rotary swaging process. J. Mater. Process. Technol. 2009, 209, 283-288. [CrossRef]

32. Ihkina, S.; Kuhfuss, B.; Schenck, C. Influence of the relative rotational speed on component features in micro rotary swaging. MATEC Web Conf. 2015, 21, 09012. [CrossRef] 